\title{
Climbing the co-evolution ladder
}

\section{Co-evolution: Earth history involves tightly entwined transitions of information and the environment, but where is this process heading?}

\section{T. M. Lenton, H. J. Schellnhuber} and E. Szathmáry

$\mathrm{S}$ tanislav Lem's science-fiction masterpiece, Solaris, tells the gripping and scary - story of a super-intelligent super-organism that has transmuted into a vast ocean covering most of the surface of a distant planet. Thus informationprocessing (that is, active) life and force-driven (that is, passive) environment have finally merged into a single entity.

Here on Earth, we have yet to reach this vanishing point of evolutionary history. But modern civilization already perturbs - if not dominates - various large-scale processes and components of the planet. Most notably, the global 'metabolism' (the cycling of essential elements, including carbon, nitrogen, phosphorus and sulphur) and features of the global 'anatomy' (the landscape textures of the habitable continents) are largely a product of relentless socioeconomic action.

Within the framework of Earth system analysis, this can be perceived as the latest step on the grand co-evolutionary ladder of entwined transitions of information and environment. Global industrialization, particulary since the Second World War, induced the transition into the Anthropocene. Its environmental consequences may in turn provoke a transition to an even higher form of worldwide socio-political organization.

Extending our concept of entwined transitions further back in time, we soon encounter the rise of the 'hydraulic societies' in the valleys of the Nile, Euphrat, Tigris and Indus, which were probably founded in response to the great drying of the African-Asian regions that took place in the sixth millennium before present (BP). Before this, organized Homo sapiens hunting caused mass extinctions of the prehistoric fauna. Language provided the novel inheritance system that allowed cumulative cultural and technological evolution, and a society resting on complex, negotiated division of labour. Further back, the evolution of hominins in the East African Rift valley was shaped by a rapidly changing environment.

Entwined environment-information transitions have characterized Earth's evolutionary history since its beginning some 4 billion years ago (4 Gyr). Life emerged remarkably soon after surface conditions became habitable, with the formation of oceans and cessation of sterilizing asteroid impacts. The first organisms would have

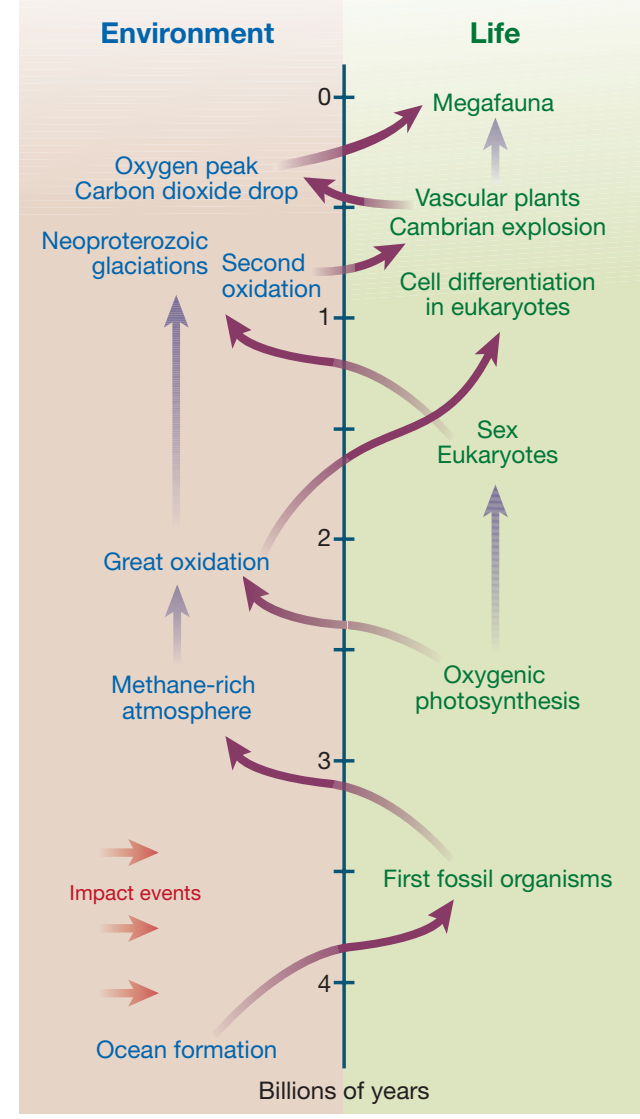

Earth's co-evolutionary ladder, as built so far...

drained the environment of energetically and structurally useful compounds and replaced them with degraded waste products, including methane. An ultimately dull fate for life, eking out a meagre existence on a lifeboat Earth, was averted when closed recycling loops developed, in which one life form's waste became another's food. These loops are large-scale manifestations of the auto-catalytic nature of the cell, locked in as the core of the global 'metabolism' that is still with us.

Despite recycling, life remained energetically limited until the origin of oxygenic photosynthesis, sometime before 2.7 Gyr. This breakthrough in metabolic evolution greatly increased the free energy supply to the biota, giving life a truly global environmental impact. It facilitated the great oxidation of the atmosphere around 2.2 Gyr, but — as the long time lag indicates - other factors were required. Perhaps oxidation had to await tectonically driven changes in Earth's 'anatomy', including the appearance of shelf seas where reduced organic carbon could reach the sediments and be buried.
Although the energetic stage was now set for global dominance by eukaryotes, the emergence of a soft cellboundary membrane coupled to an internal skeleton and a means for cellular division were also required. These transitions are thought to have been especially difficult, as they required the fixation of thousands of rare mutations.

Eukaryotes may be implicated in the worst crisis of past co-evolution: the extreme Neoproterozoic glaciations of $0.8-0.6$ Gyr that were accompanied by a second rise in oxygen. Whenever eukaryotes started to colonize the land surface, there would have been strong selection for traits that accelerated weathering to access rock-bound nutrients. Weathering of silicates would have inadvertently drawn down atmospheric carbon dioxide and cooled the planet, and weathering of phosphorus would have increased global productivity and contributed to oxygen rise. The latter opened the door for the diversification of larger, hard-shelled, animal life in the Cambrian explosion. After that, the triumph of vascular land plants, causing a further rise in oxygen and fall in carbon dioxide, played its part in creating the environmental conditions in which active megafauna (including ourselves) evolved.

Pursing this concept of entwined evolution may reveal where we are ultimately heading - towards Solaris, or something even scarier.

T. M. Lenton and H. J. Schellnhuber are in the Tyndall Centre, UK, and the School of Environmental Sciences, University of East Anglia, Norwich NR4 7TJ, UK. E. Szathmáry is at the Collegium Budapest, 2 Szentharomsag utca, H-1014 Budapest, Hungary.

\section{FURTHER READING}

Schellnhuber, H. J. et al. (eds.) Earth System Analysis for Sustainability (Dahlem Workshop Reports 91, MIT Press, 2004).

Lovelock, J. E. The Ages of Gaia - A biography of our living Earth (Oxford Univ. Press, 1988).

Maynard Smith, J. \& Szathmáry, E. The Major Transitions in Evolution (Freeman, 1995).

Lenton, T. M. \& Watson, A. J. Geophysical Research Letters 31, L05202 (2004).

Schellnhuber, H. J. Nature 402, C19-C23, (1999). Crutzen, P. J. Nature 415, 23 (2002).

Based on the 91st Dahlem Workshop on Earth System Analysis for Sustainability, Berlin, 25-30 May 2003, with thanks to our fellow participants. 